\title{
Fuel Properties Effect on the Performance of a Small High Temperature Rise Combustor
}

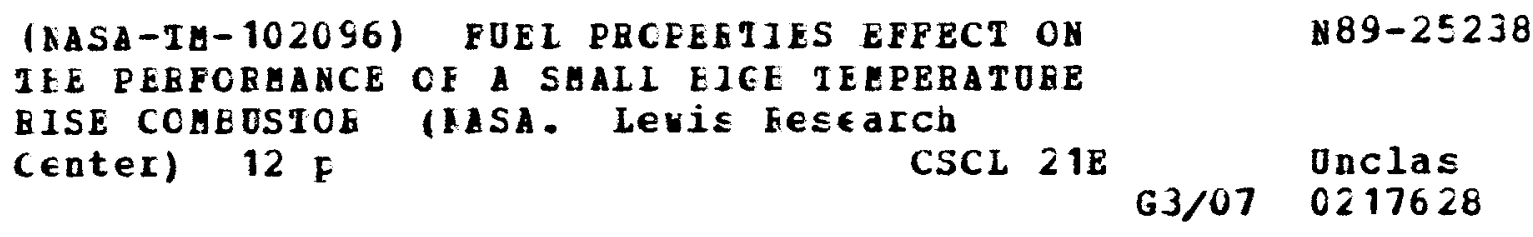

Waldo A. Acosta

Propulsion Directorate

U.S. Army Aviation Research and Technology Activity-AVSCOM

Lewis Research Center

Cleveland, Ohio

and

Stephen A. Beckel

Pratt \& Whitney Aircraft

West Palm Beach, Florida

Prepared for the

25th Joint Propulsion Conference

cosponsored by the AIAA, ASME, SAE, and ASEE

Monterey, California, July 10-12, 1989 
FUEL PROPERTIES EFFECT ON THE PERFORMANCE OF A SMALL HIGH TEMPERATURE RISE COMBUSTOR*

\author{
Waldo A. Acosta \\ Propulsion Directorate \\ U.S. Army Aviation Research and Technology Activity - AVSCOM \\ Lewis Research Center \\ Cleveland, Ohio \\ and
}

Stephen A. Beckel

Government Products Division

Pratt \& Whitney Aircraft

West Palm Beach, Florida

\section{Abstract}

The performance of an advanced small high temperature rise combustor was experimentally determined at the NASA Lewis Research Center. The combustor was designed to meet the requirements of advanced high temperature, high pressure ratio turboshaft engines. The combustor featured an advanced fuel injector and advanced segmented liner design. The full size combustor was evaluated at power conditions ranging from idle to maximum power. The effect of broad fuel properties was studied by evaluating the combustor with three different fuels. The fuels used were JP-5, a blend of Diesel Fuel Marine/Home Heating Oil (DFM/HHO), and a blend of Suntec C/Home Heating Oil (SunC/HHO). This paper documents the fuel properties effect on the performance of the combustor in terms of pattern factor, liner temperatures, and exhaust emissions.

\section{Introduction}

The effect of fuel type on the performance of a small high temperature rise combustor was investigated at the NASA Lewis Research Center. Combustor performance and emissions were documented for a JP-5 baseline fuel and two alternative fuels, a blend of Diesel Fuel Marine/Home Heating O1T (DFM/HHO) and a blend of Suntec C/Home Heating Oil (SunC/HHO).

As domestic sources of high quality crudes diminish, coupled with increased competition for the middle distillates, jet aviation fuel specifications may require modification or relaxation to ensure adequate supplies. For any given application, the optimum gas turbine fuel is one that represents the best compromise solution to the various problems confronting the oll companies, the engine and aircraft manufacturers, and the operator. For the civil operator the main requirements are safety, reliability, low cost, and ease of handing. For the military, cost is of secondary importance compared with availability, supply logistics and the need for trouble free operation over a wide range of conditions.

Relaxation of fuel specifications could adversely affect aircraft engine performance and durability. The effect of fuel properties is not constant for all combustors. The performance with alternate fuel changes from one combustor to another due to differences in operating conditions and design. In general, fuel properties effect on the combustor performance can be classified as physical or chemical in nature.
Fuel physical properties that govern atomization and evaporation rates will affect ignition characteristics, lean-blowout 1 imits, combustion efficiency, unburned hydrocarbons, and carbon monoxide emissions. These parameters, and thermal nitric oxide emissions, are nearly unaffected by fuel chemistry, as indicated by hydrogen content and/or aromatic content.

Flame radiation, liner wall temperature, and smoke emissions are more dependent on the chemical properties of the fuel specially in regard to hydrogen and aromatics content. Concerning the actual combustion process, there is only a slight variation in the chemical reaction rates between the various hydrocarbon fuels of interest to the aircraft gas turbine industry. The reason being the slight differences in adiabatic flame temperature and the fact that before entering the true reaction zone all the fuels are largely pyrolized to methane, other 1-2 carbon atom hydrocarbons, and hydrogen. This makes the gas composition in the reaction zone nearly independent of the fuel injected.

Since the 1970's, the Air Force, Army, Navy, NASA, General Electric, Pratt \& Whitney, and other engine manufacturers have conducted analytical and experimental programs to determine the effects of anticipated future fuels on existing engines. Some of the results can be found in Refs. 1 to 6 .

The purpose of this joint effort involving the Navy, Army, NASA, and Pratt \& Whitney was to quantify the fuel properties effect on a small high temperature rise combustor specifically designed to operate on alternative fuels. This paper describes the results obtained. Performance measurements in terms of pattern factor, smoke, and combustion efficiency were acquired at combustor exit temperature conditions up to $1825 \mathrm{~K}\left(2825^{\circ} \mathrm{F}\right)$ with $\mathrm{JP}-5$ and two alternative fuels. Additionally, the combustor was instrumented with imbedded metal thermocouples, and a set of radiometers were installed to quantify fuel properties effects on the radiant heat loads to the combustor walls.

\section{Apparatus}

\section{Test Facility}

The combustor was mounted in duct $A$ of the test facility CEgB (Fig. 1) located in the Engine Research Building (BIdg. 5) at NASA Lewis. The laboratory air supply can maintain airflow rates up 
to $15 \mathrm{~kg} / \mathrm{sec}(33 \mathrm{lb} / \mathrm{sec})$ at pressure levels up to $30 \mathrm{~atm}$. Tests were conducted with inlet air pressure ranging up to $20 \mathrm{~atm}$ with the air indirectly heated to about a temperature of $725 \mathrm{~K}\left(850^{\circ} \mathrm{F}\right)$ in a counterflow tube heat exchanger. The hot gases were provided by four J-47 combustor cans burning natural gas. The temperature of the air was automatically controlled by mixing the heated air with varying amounts of cold by-pass air. Airflow through the heat exchanger and by-pass flow system and the total pressure of the combustor were regulated by remotely controlled valves.

\section{Combustor}

The full-annular combustor rig used in this program is designed to simulate a 2983 to $5220 \mathrm{~kW}$ ( 4000 to $7000 \mathrm{shp}$ ) class turboshaft/prop type engine combustion system. The combustor featured an advanced segmented liner design. The rig consists of inlet, combustor, and exhaust cases capable of withstanding full-engine operating conditions of 20 atm and $840 \mathrm{~K}\left(1050^{\circ} \mathrm{F}\right.$ ) (diffuser exit conditions). A water-cooled exhaust transition duct was also fabricated to mounting of the rig to the NASA facility. An advanced fuel injector design developed under a Navy contract with Pratt \& Whitney was used in this experimental program (Contract N00140-83-C-8899).

Fuels

The fuels used in the experimental program were JP-5, Diesel Fuel Marine/Home Heating Oil (DFM/HHO) blend, and Suntec C/Home Heating Oil (SunC/HHO) blended fuels. The fuels were chosen to provide a range fuel properties typical of broadened specification fuels of the future. The fuel properties are presented in Table 1.

\section{Instrumentation}

The instrumentation required to support the high-pressure full-annular rig testing measured air and fuel flow, diffuser air temperature and pressure, combustor liner pressure drop, and exhaust gas emissions, temperature and pressure. To ensure adequate safety and longevity of the combustor rig and facility, the temperature of the cooling air and water was measured. Rig and exhaust duct metal temperatures were also measured.

Combustor instrumentation locations are shown schematically in Fig. 2. Sensor redundancy was provided at all axial locations to ensure measurement accuracy. Combustor exit conditions were measured with a rotating traverse probe. The traverse probe consists of two platinum/rhodium thermocouple rakes located at 180 degrees from each other and an emissions rake. Thermocouple and emissions probes for each rake were positioned at five radial locations. Measurements were taken every $1.98^{\circ}$ (seven readings per fuel injector $/ 182$ data points) for a full $360^{\circ}$ sweep. Temperature data were acquired up to the temperature limit of the thermocouple rake that was estimated to be at a hot spot temperature of $2033 \mathrm{~K}$ $\left(3200^{\circ} \mathrm{F}\right)$.

The combustor liner was instrumented with 24 imbedded thermocouples. Each 1 iner had 12 thermocouples at 2 circumferential positions and 6 axial locations. Two porous-plug radiometer probes were installed to measure radiant heat flux to the combustor walls.

\section{Procedure}

\section{Test Conditions}

The small high temperature rise combustor was operated at test conditions based on a gas turbine engine cycle with a compressor pressure ratio of 20 . Due to facility limitations, some of the high power conditions were run at a lower inlet temperature than their design condition. For those conditions, the fuel air ratio was increased to achieve the design temperature rise and exit temperature. A tabulation of the test conditions used in this study is given in Table 2.

\section{Emissions Measurements}

Exhaust gas samples were obtained according to the procedures recommended in Refs. 7 and 8 . Exhaust gases were withdrawn through the rotating probe mounted at the exit of the combustor. The gas sample temperature was held at approximately $425 \mathrm{~K}$ $\left(305^{\circ} \mathrm{F}\right)$ in the electrically heated sampling line. Most of the gas sample entered the analyzer oven. while the excess sample was bypassed to the exhaust system. To prevent fuel accumulation in the sample line, a nitrogen purge was used before and during combustor ignition.

After passing through the analyzer oven the gas sample was divided into five parts, and each part was analyzed. Concentrations of oxides of nitrogen, carbon monoxide and carbon dioxide, and hydrocarbons were measured by the chemiluminescence, nondispersedinfrared, and flame ionization methods, respectively. oxygen concentrations were measured using a polarographic sensor.

Smoke measurements were acquired at five discrete circumferential positions oriented in-line, and between injectors to establish an average reading. Two or three samples per position were obtained. The smoke probe was configured as a ganged rake with sample ports oriented at four radial locations. The SAE smoke number was calculated following the procedures recommended in Ref. 9.

\section{Results and Discussion}

Combustor research relating to the development of fuel efficient small gas turbine engines capable of meeting future commercial and military aviation needs is currently underway at NASA Lewis. A small high temperature rise combustor incorporating an advanced segmented liner and fuel injector design was experimentally evaluated at power conditions up to $20 \mathrm{~atm}$ pressure ratio and exhaust temperatures up to $1825^{K} \mathrm{~K}\left(2825^{\circ} \mathrm{F}\right)$. The combustor was run on JP-5, Diesel Fuel Marine/Home Heating Oil (DFM/HHO) blend, and Suntec C/Home Heating Oil (SunC/HHO) blended fuels.

\section{Emissions and Combustion Efficiency}

Emissions measurements were acquired at conditions up to 100 percent power condition. Combustion efficiencies greater than 99.9 percent were measured at all power conditions above idle for all the fuels. Idle efficiency was lower at 85 percent.

Although emission levels are not currently required for small gas turbine engines, the emission 
levels are an indication of the effectiveness of the combustion process in relationship to the internal flow and mixing dynamics. Emission index is defined as the grams of pollutant per kilogram of fuel burned. The emission index for unburned hydrocarbons was less than one (1.0) and less than three (3.0) for carbon monoxide at high power conditions. At idle, the emission index of unburned hydrocarbons and carbon monoxide increased in accordance with the loss in combustion efficiency. No fuel type effect was observed.

Smoke

One way to determine if a combustor is operating satisfactorily is by measuring the amount of particulate in the exhaust. It is very important for the military and commercial aircraft to operate without any visible smoke emissions. Smoke is the product of finely-divided soot particles in fuelrich zones of the combustion flame. It could also be produced anywhere in the combustion zone where mixing is inadequate. For all practical purposes, the combustor may be divided in two separate zones, first, the primary zone, which governs the rate of soot formation and, second, the dilution zone, which determines the rate of soot consumption or oxidation. Most of the soot produced in the primary zone is consumed in the high temperature regions downstream. Thus, the soot concentration measured at the exit of the combustor is an indication of the strength of one zone over the other.

Smoke production can be influenced by the physical and chemical properties of the fuel. Physical properties such as volatility and viscosity which affect the mean drop size, penetration and evaporation of the fuel spray, control the formation of local fuel-rich regions. Chemical properties, which are related to molecular structure, will control the resistance to carbon or soot production of each different fuel.

The effect of fuel type on the measured SAE smoke number is shown in Fig. 3. For this particular combustor the experimental smoke data correlates very well with the amount of hydrogen in the fuels. The results confirm the well established tendency that smoke increases with reductions in hydrogen content. 10,11 other studies have shown that fuels containing high concentrations of polycyclic aromatics produce more smoke than those containing low concentrations.12,13 The fuel type effect diminished as the power level increased as shown by the slope of the curves for each power condition.

The combustor operating conditions that affect smoke production are pressure, temperature, and primary zone equivalence ratio. The effect of pressure is more severe at high power conditions. The increase in pressure creates more ideal conditions for the production of smoke. For example, the flammability limits are extended and soot is produced in regions that otherwise would be too rich to burn, also an increase in pressure speed up the reaction rates and combustion is initiated earlier and in fuel-rich regions adjacent to the fuel spray. Pressure increases also tends to reduce the spray angle raising the mixture strength in the soot forming region. The effect of inlet temperature is not well understood, but increases in combustor exit temperature help to oxide the soot formed in the primary zone. Increasing the primary zone equivalence ratio without improving the fuel-air distribution will increase the smoke production by creating more local fuel-rich zones.

The smoke correlation parameter (SCP) provides a good correlation of the SAE smoke number and the combustor operating conditions as shown in Fig. 4. The smoke correlation parameter (SCP) is defined as:

$$
S C P=\phi \cdot P_{t 3} /\left(T_{t 3}\right)^{1 / 2}
$$

where

$\phi$ front end equivalence ratio

$P_{t 3}$ combustor inlet pressure

$\mathrm{T}_{\mathrm{t} 3}$ combustor inlet temperature

Even though there is not a clear understanding of the effect of inlet temperature on the SAE smoke number, from the definition it could be inferred that holding everything else constant, an increase in combustor inlet temperature would result in a reduction in the SAE smoke number. For a fixed inlet pressure and equivalence ratio, increasing the inlet temperature results in an increase in the gas temperature, which helps to oxidize the soot formed in the primary zone. Since the combustor was operated at off-design condition due to facility limitations (low inlet temperature), and SCP was calculated for true design condition as shown in Fig. 5. This result indicates that this combustor would provide a design smoke number of less than 15 for the range of fuel properties tested, which is below the visibility limits.

\section{Pattern Factor}

Complete combustor exit temperature data were acquired at power level conditions up to IRP for all three fuels. The pattern factor was calculated according to:

$$
P F=\frac{T_{\text {t4max }}-T_{\text {t4eqave }}}{T_{\text {t4eqave }}-T_{\text {t3 }}}
$$

where

Tt4max maximum exit temperature (Weibull analysis) 14

Tt4eqave equilibrium average exit temperature

$T_{t 3}$ combustor inlet temperature

Weibull analysis and equilibrium average exit temperature were used to compensate for any temperature measurement error. The equilibrium average exit temperature was calculated based on measured combustor inlet conditions and fuel/air ratio. 15

The results, as a function of combustor temperature rise, are shown in Fig. 5. Pattern factors of $0.25 \pm 0.02$ were demonstrated for all fuels when operating at high-power levels. No appreciable fuel effect is shown over the range of conditions tested. The pattern factor is affected by the fuel type through the effects of viscosity and surface tension on droplet evaporation time. At the operating conditions studied, the evaporation time was a small 
fraction of the total combustor residence time despite of the fuel type and not appreciable effect on pattern factor was observed.

Earlier studies found that pattern factor has a tendency to increase as hydrogen content is decreased. 6 This was attributed to the formation of carbon deposits in the swirl cup and disrupting the fuel spray. Inspection of the fuel nozzles after testing showed no carbon deposits. The pattern factor results obtained in this study demonstrate that the advanced fuel nozzle design can tolerate different types of fuels with a wide range of properties.

\section{Liner Temperature}

Heat is first transferred to the combustor liners by convection and radiation from the hot gases inside it. Then, heat is transferred away from the liner by convection to the air in the annulus between the liner and the outer casing and by radiation from the liner to the combustor casing. The geometry and physical dimensions of the combustor, and the operating conditions will determine the ratio between the convection and radiation heat transfer mechanisms.

In this study, the effect of fuel type on the radiative heat flux was studied using a porous plug type radiometer probes. The measured radiant heat flux is shown in Fig. 6 as a function of percent hydrogen content for each power condition tested. The radiant heat flux increased with reductions in hydrogen content and increases in power level. The rate at which the radiant heat flux increases with reductions in hydrogen content is almost constant for the 40,60 , and 80 percent power conditions, but it starts to change with the 100 percent power condition and at the maximum combustor exit temperature condition the effect of fuel type on heat flux is very small as shown in Fig. 6. For each fuel tested, a reduction in hydrogen content was associated with an increase in aromatics content. As discussed earlier, increases in aromatics content are directly related to increases in soot production. The same principles discussed for the effect of fuel properties on smoke apply to radiant heat flux.

The effect of fuel type on liner temperature is shown in Fig. 7. The temperature measurements presented in Fig. 7 were made at the trailing edge of the first liner segment on the inner liner. The temperatures shown are all from the same thermocouple. That is one of the reasons why the measured liner temperatures do not increase the same way that the radiative heat transfer flux does. The heat flux probe used in this experimental program had a fairly wide view angle making it less sensitive to local changes in the concentration of the soot particles due to changes in the fuel spray pattern and combustor operating conditions. Another reason may be the reduction in inlet temperature experienced due to facility limitations. The lower inlet air temperature provided more heat sink capability.

It is shown in Fig. 7 that for each power condition studied, the liner temperature increases with increasing aromatics content (reducing hydrogen content). The liner temperatures for SunC/HHO, the fuel with the lowest hydrogen content and highest aromatic content, were higher than DFM/HHO and JP-5 at every power condition studied. Likewise, the liner temperatures for DFM/HHO fuel, which has higher aromatics and lower hydrogen content than $\mathrm{JP}-5$, are higher than $\mathrm{JP}-5$ fuel and lower than SunC/ HHO fuel.

An advanced segmented liner design concept providing good durability and life characteristics with minimal cooling requirements was used in this study. In this liner design concept, the panels or shingles provide thermal protection to the load-carrying support structure. The individual panels are mounted on the support structure. With this method, the panels are mechanically decoupled from the relatively cool support structure resulting in reduced thermal stress levels within the liner structure and dramatically improved liner cyclic life characteristics. The durability of the segmented liner design concept is determined by the temperature capability of the material used to fabricate the panels. The material used in this study had a temperature limit of $1256 \mathrm{~K}\left(1800^{\circ} \mathrm{F}\right)$. Post-test inspection revealed signs of corrosion at the trailing edge of the first inner liner segment (the one nearest to the fuel injector) indicating that the temperatures at the location exceeded the $1256 \mathrm{~K}$ limit. Liner temperatures greater than $1200 \mathrm{~K}\left(1700^{\circ} \mathrm{F}\right)$ were measured on the first panels of the outer liner, but little evidence of metal erosion was observed. The remaining panels were found to be in excellent condition and liner temperatures below $1090 \mathrm{~K}\left(1500^{\circ} \mathrm{F}\right)$ were recorded for all power conditions.

\section{Summary of Results}

1. No discernible fuel effect was observed for pattern factor, gaseous emissions, or combustion efficiency.

2. In general, SAE smoke number, radiant flux, and liner metal temperatures increase with power level and decreasing fuel hydrogen content.

3. The sensitivity of smoke production and radiant heat flux to fuel hydrogen content is relatively constant over the range of conditions tested.

4. The carbon-free operation of the advanced fuel injector during this test series, confirms the fuel tolerance capability of the design.

5. Except for some first I.D. panel trailingedge erosion, the segmented combustor liner exhibited durable fuel-tolerant capability.

\section{References}

1. Gleason, C.C., 01 ler, T.L., Shayeson, M.W., and Bahr, D.W., "Evaluation of Fuel Character Effects on the F101 Engine Combustion System", AFAPL-TR-79-2018, June 1979. (Avai1. NTIS, AD-A077860).

2. Beal, G.W., "Effect of Fuel Composition on Navy Aircraft Engine Hot Section Components", NAPC-PE-74C, PWA/GPD/FR-16456, Pratt \& Whitney Aircraft, West Palm Beach, FL, May 1983. (Avail. NTIS, AD-B074285L).

3. Morton, H.L., "Effects of Fuel Composition on Navy Aircraft Engine Hot Section Components," NAPC-PE-1117C, General Electric Co., Lynn, MA, Sept. 1986. (Avail. NTIS, AD-B105971L). 
4. Dodds, W.J., and Ekstedt, E.E., "BroadSpecification Fuels Combustion Technology Program," NASA CR-168179, 1983.

5. Lohmann, R.P., and Jeroszko, R.A., "BroadSpecification Fuels Combustion Technology Program, Phase I," PWA-5719-34, Pratt \& Whitney. East Hartford, CT, 1983, NASA-CR-168180.

6. Hill, T.J., Monty, J.D., and Morton, H.L., "Analytical Fuel Property Effects - Small Combustors, Phase II," R85AEB014, General Electric Co., Lynn, MA, 1985, NASA CR-174848.

7. "Control of Air Pollution from Aircraft and Aircraft Engines, Emission Standards and Test Procedures for Aircraft," Federal Register, Vol. 38, No. 136, Pt. 2, July 17, 1973, pp. 19088-19103.

8. "Procedure for the Continuous Sampling and Measurement of Gaseous Emissions from Aircraft Turbine Engines," SAE ARP-1256, Oct. 1971.

9. "Aircraft Gas Turbine Engine Exhaust Smoke Measurement," SAE ARP-1179, May 1970.

10. Butze, H.F., and Ehlers, R.C., "Effect of Fuel Properties on Performance of a Single Aircraft Turbojet Combustor," NASA TM X-71789, 1975.
11. Blazowski, W.S., and Jackson, T.A., "Evaluation of Future Jet Fuel Combustion Characteristics," AFAPL-TR-77-93, July 1978. (Avail. NTIS, $A D-A 060218$ ).

12. Naegli, D.W., Dodge, L.G., and Moses, C.A., "The Sooting Tendency of Fuels Containing Polycyclic Aromatics in a Research Combustor," Journal of Energy, Vol. 7, No. 2, Mar.-Apr. 1983, pp. 168-175.

13. Naegli, D.W., and Moses, C.A., "Effect of Fuel Molecular Structure on Soot Formation in Gas Turbine Engines," ASME Paper 80-GT-62, Mar. 1980.

14. Abernethy, R.B., Breneman, J.E., Medlin, C.H., and Reinman, G.L., "Weibull Analys is Handbook," AFWAL-TR-83-2079, Nov. 1983. (Avai 1. NTIS; $A D-A 143100$ ).

15. Gordon, S., and MCBride, B.J., "Computer Program for Calculation of Complex Chemical Equilibrium Compositions, Rocket Performance, Incident and Reflected Shocks, and ChapmanJouguet Detonations," NASA SP-273, 1976.

TABLE I. - FUEL PROPERTIES

\begin{tabular}{|c|c|c|c|}
\hline Parameter & $J P-5$ & DFM/HHO & SUN C/HHO \\
\hline $\begin{array}{l}\text { Specific gravity at } 288 \mathrm{~K}\left(59^{\circ} \mathrm{F}\right) \\
\text { Net heating value, } \mathrm{J} / \mathrm{g}(\mathrm{Btu} / \mathrm{lb}) \\
\text { Aromatics, vol \% } \\
\text { Olefins, vol \% } \\
\text { Sulfur, wt \% } \\
\text { Hydrogen, wt \% } \\
\text { Distillation, } \mathrm{K}\left({ }^{\circ} \mathrm{F}\right) \\
\text { IBP } \\
10 \text { percent } \\
20 \text { percent } \\
50 \text { percent } \\
90 \text { percent } \\
\text { EP percent } \\
\text { Viscosity at } 311 \mathrm{~K}\left(100^{\circ} \mathrm{F}\right), \mathrm{m} 2 / \mathrm{s} \text { (cs) } \\
\text { Surface tension }\end{array}$ & $\begin{array}{r}0.817 \\
43025(18483) \\
22.1 \\
0.70 \\
0.02 \\
13.67 \\
\\
458(364) \\
472(390) \\
478(400) \\
490(423) \\
513(464) \\
533(499) \\
1.58 \times 10^{-6}(1.58) \\
20.4\end{array}$ & $\begin{array}{r}0.844 \\
42661(18327) \\
26.0 \\
0.90 \\
0.35 \\
13.31 \\
\\
466(379) \\
502(444) \\
516(468) \\
546(522) \\
594(610) \\
606(630) \\
3.08 \times 10^{-6}(3.08) \\
26.8\end{array}$ & $\begin{array}{r}0.859 \\
42228(18(141) \\
37.1 \\
0.50 \\
N / A \\
12.45 \\
\\
450(351) \\
476(397) \\
482(408) \\
504(448) \\
579(583) \\
618(653) \\
1.99 \times 10^{-6}(1.99) \\
28.8\end{array}$ \\
\hline
\end{tabular}

TABLE II. - SMALL HIGH TEMPERATURE RISE COMBUSTOR TEST CONDITIONS

\begin{tabular}{|l|c|c|c|c|c|}
\hline $\begin{array}{c}\text { Power } \\
\text { condition, } \\
\text { percent }\end{array}$ & $\begin{array}{c}\text { Combustor } \\
\text { airflow, } \\
\mathrm{kg} / \mathrm{s}(1 \mathrm{~b} / \mathrm{s})\end{array}$ & $\begin{array}{c}\text { Inlet } \\
\text { pressure, } \\
\mathrm{KPa}(\mathrm{psia})\end{array}$ & $\begin{array}{c}\text { Design inlet } \\
\text { temperature, } \\
\mathrm{K}\left({ }^{\circ} \mathrm{F}\right)\end{array}$ & $\begin{array}{c}\text { Actual inlet } \\
\text { temperature, } \\
\mathrm{K}\left({ }^{\circ} \mathrm{F}\right)\end{array}$ & $\begin{array}{c}\text { Fuel/air } \\
\text { ratio }\end{array}$ \\
\hline Idle & $1.90(4.2)$ & $324(47)$ & $402(264)$ & $402(264)$ & 0.008 \\
40 & $6.39(14.1)$ & $1275(185)$ & $741(874)$ & $741(874)$ & .022 \\
60 & $7.26(16.0)$ & $1510(219)$ & $774(933)$ & $774(933)$ & .025 \\
80 & $8.39(18.5)$ & $1730(251)$ & $802(983)$ & $756(900)$ & .027 \\
100 & $9.52(21.0)$ & $1937(281)$ & $828(1030)$ & $739(870)$ & .030 \\
Maximum & $10.07(22.2)$ & $2041(296)$ & $839(1051)$ & $728(850)$ & .030 \\
Maximum & $10.07(22.2)$ & $2041(296)$ & $839(1051)$ & $728(850)$ & .034 \\
CETa & & & & & \\
\hline
\end{tabular}

aMaximum combustor exit temperature. 


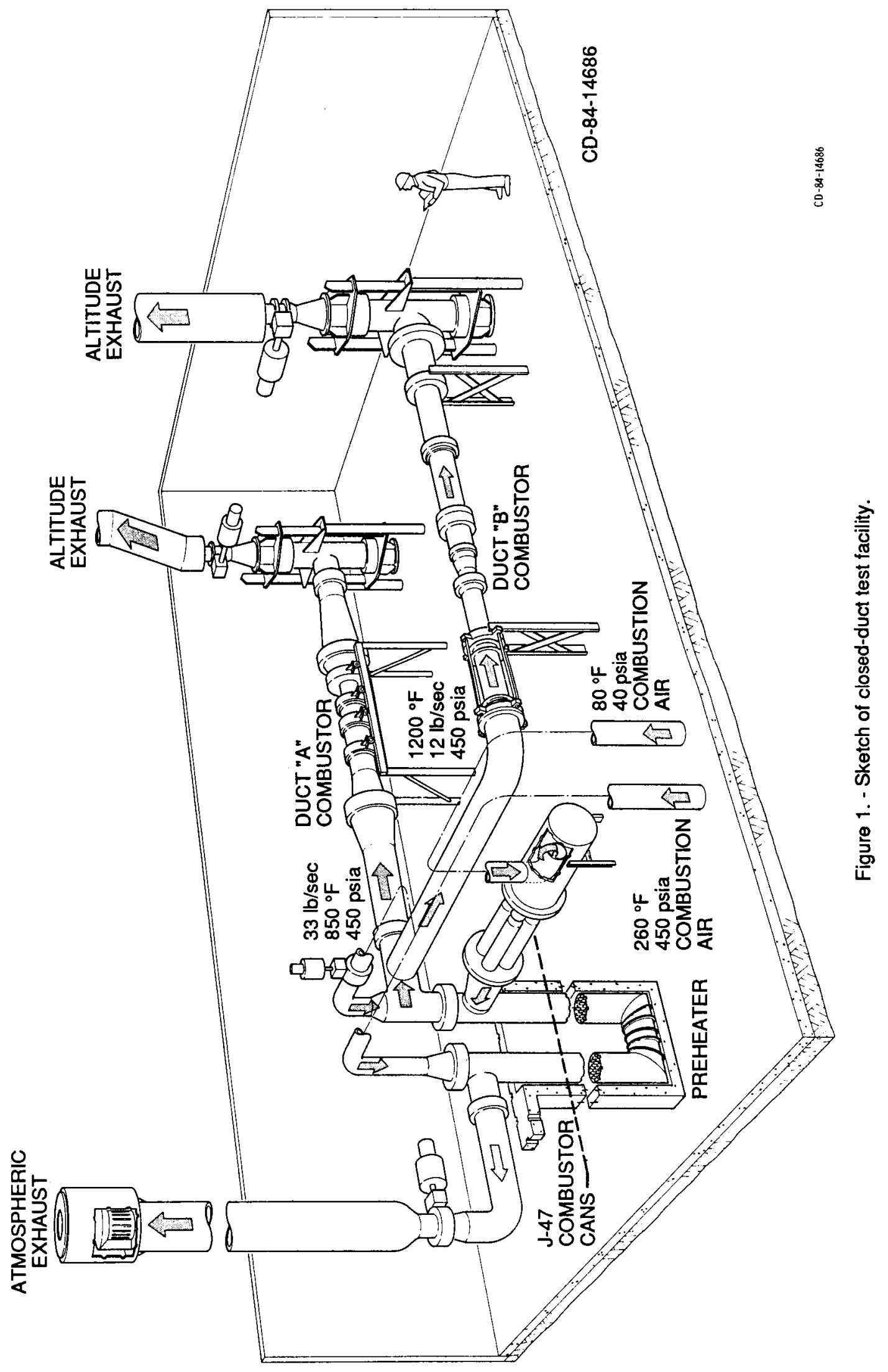




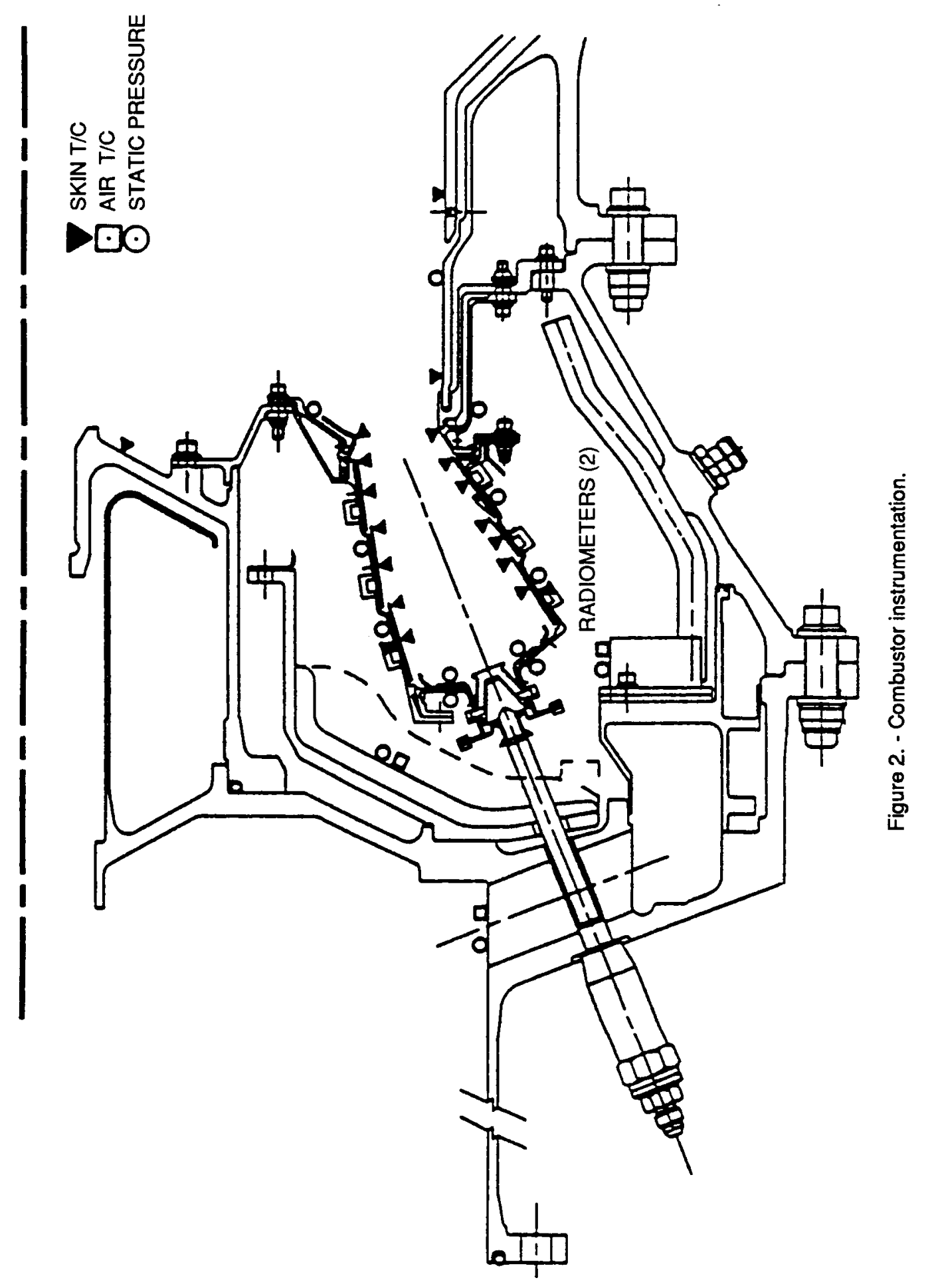




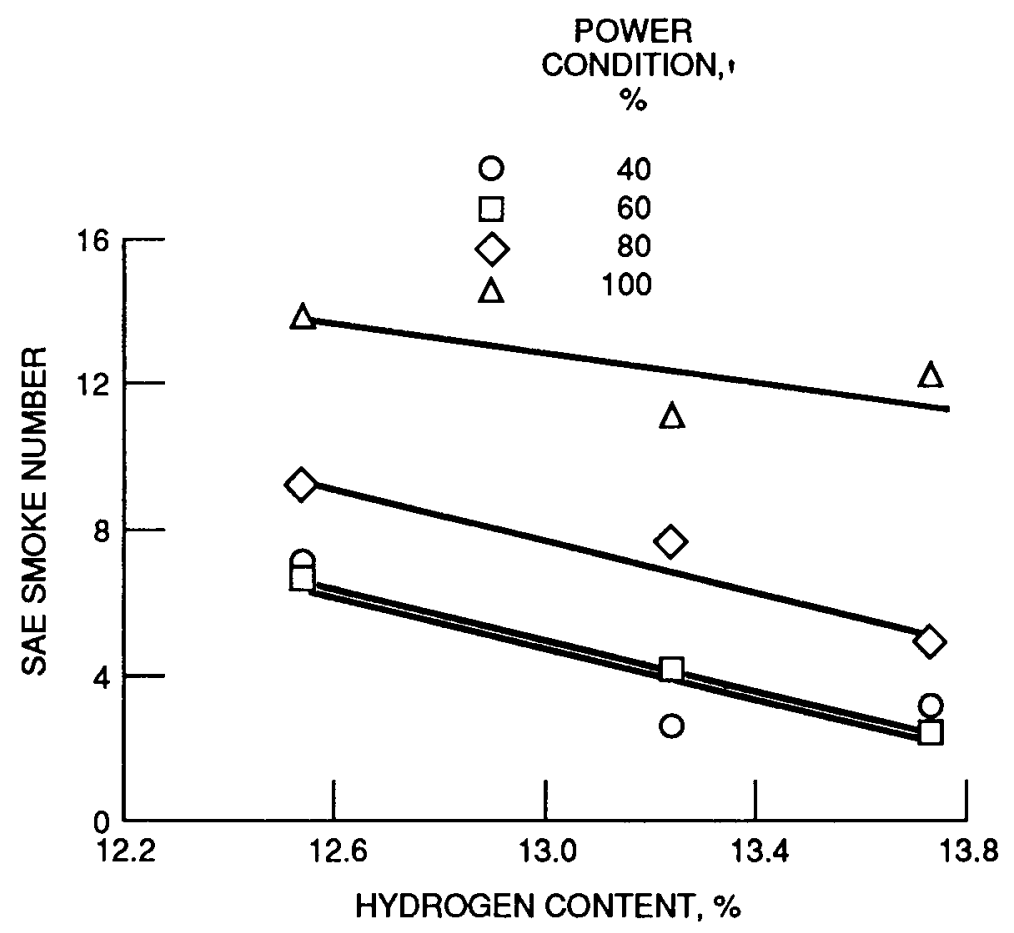

Figure 3. - Effect of fuel hydrogen content on SAE smoke number.

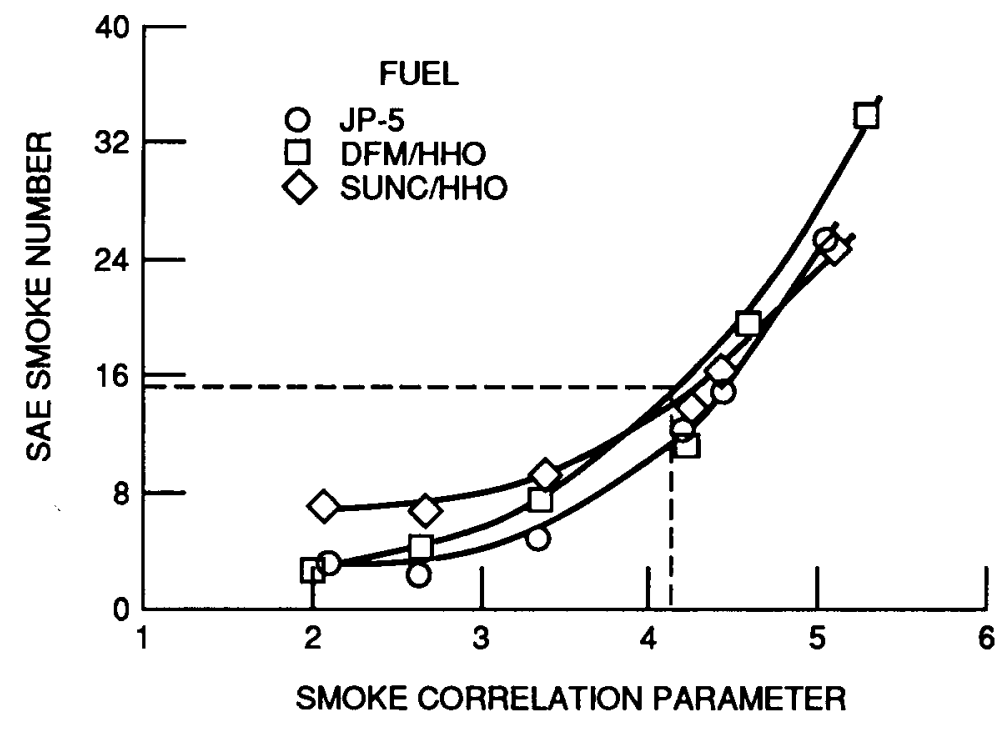

Figure 4. - Relationship between SAE smoke number and the smoke correlation parameter. 


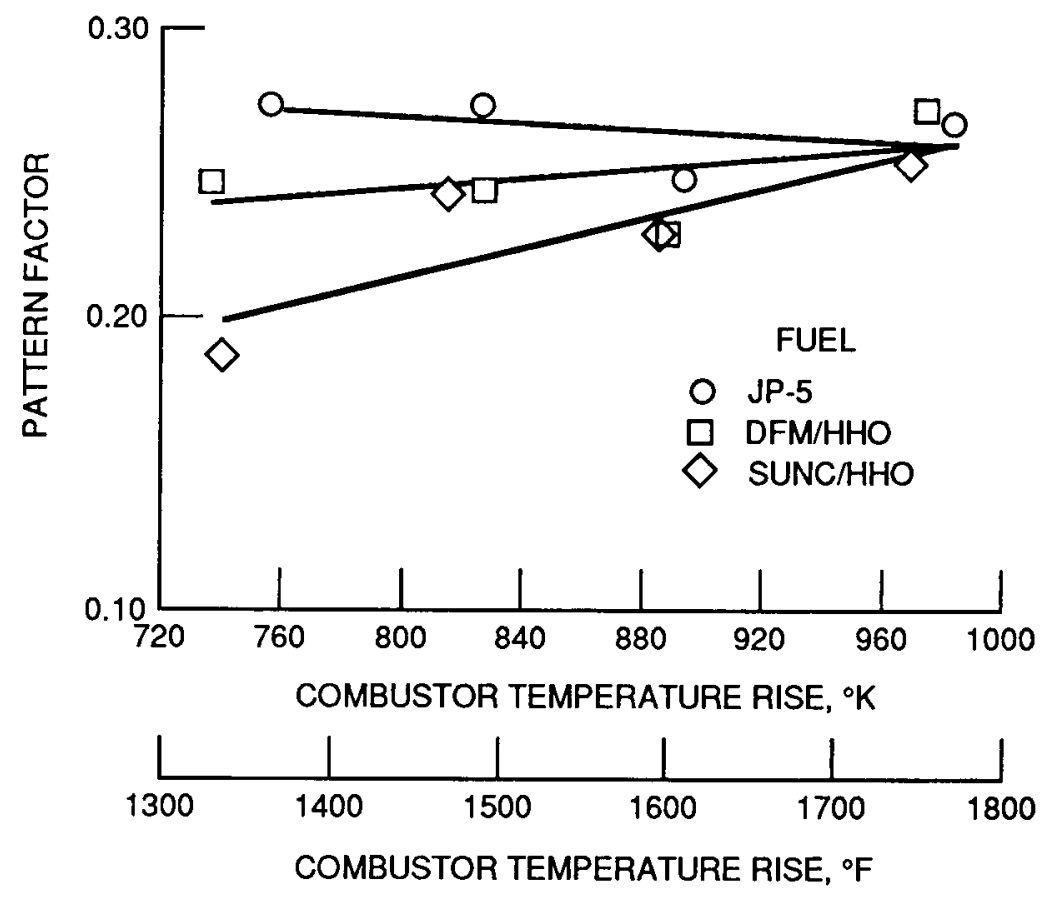

Figure 5. - Effect of combustor temperature rise on pattern factor.

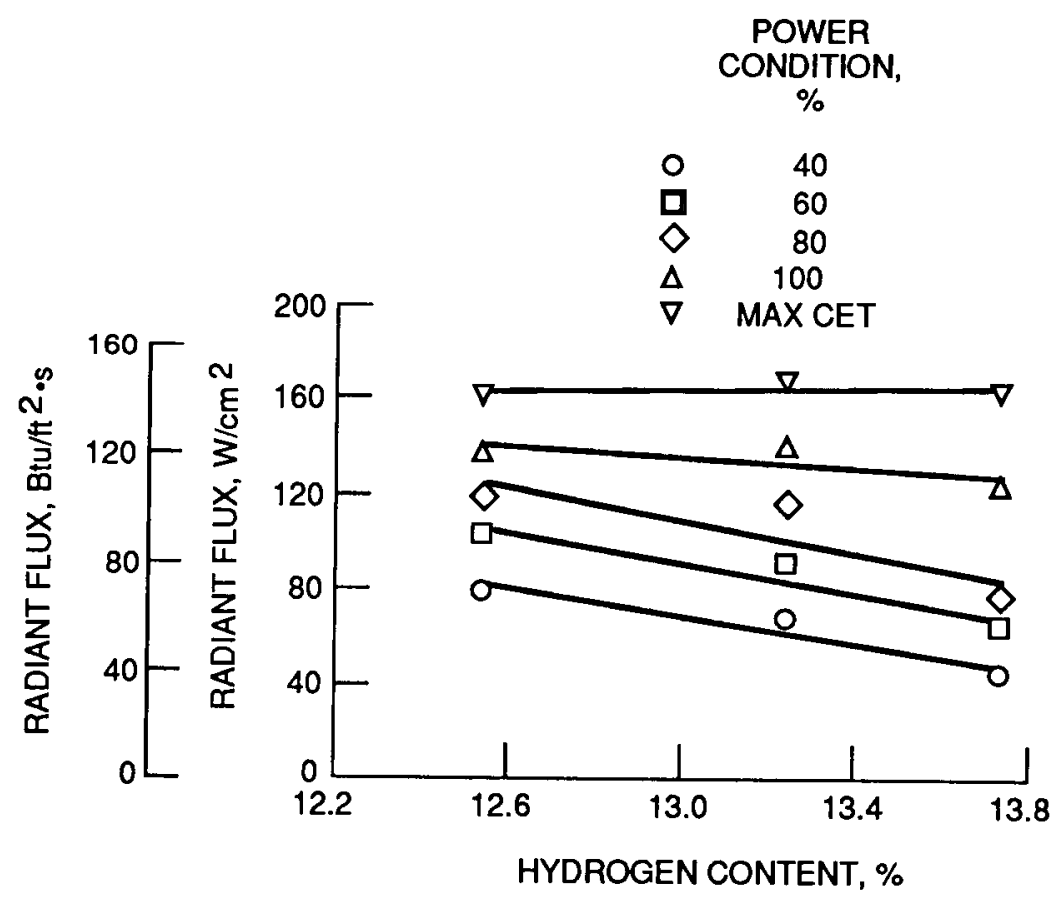

Figure 6. - Effect of fuel hydrogen content on the radiant heat flux. 

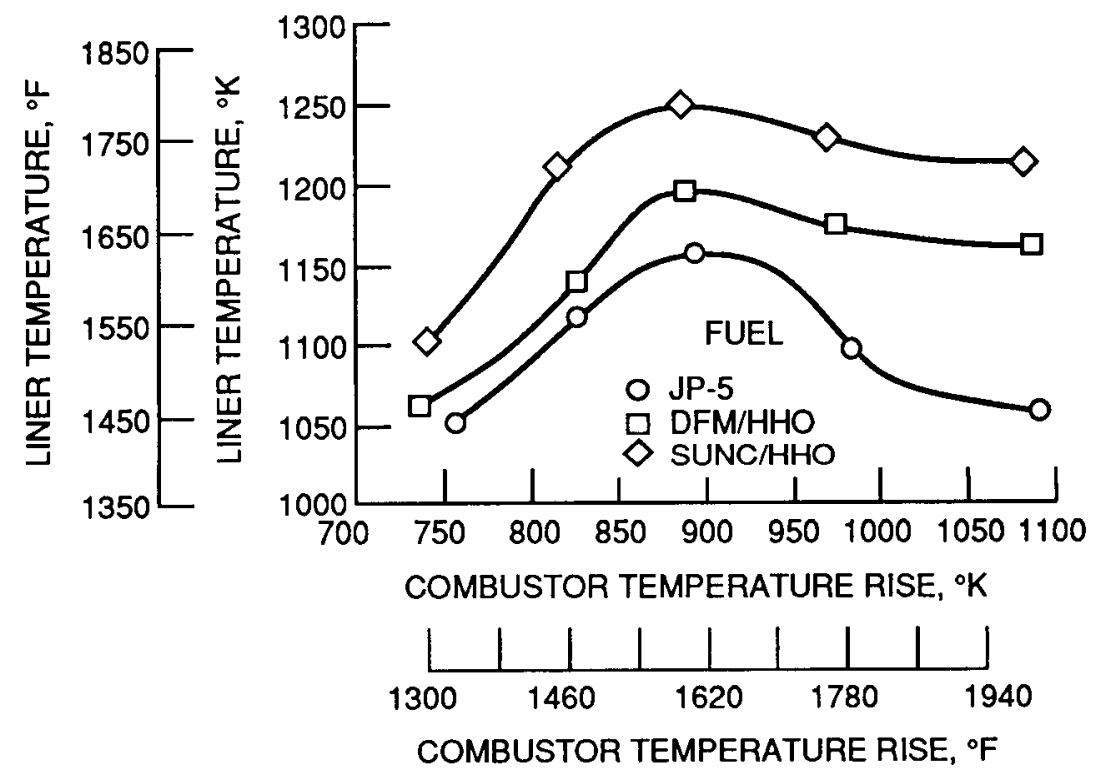

Figure 7. - Effect of combustor temperature rise on the temperature of the trailing edge of the first row of panels on the inner liner. 


\begin{tabular}{l|l|l|}
$\begin{array}{l}\text { 1. Report No. NASA TM-102096 } \\
\text { AVSCOM TR 89-C-004; AIAA-89-2901 }\end{array}$ & 2. Government Accession No. & 3. \\
\hline
\end{tabular}

4. Title and Subtitle

3. Recipient's Catalog No.

5. Report Date

Fuel Properties Effect on the Performance of a Small High Temperature

Rise Combustor

6. Performing Organization Code

7. Author(s)

Waldo A. Acosta and Stephen A. Beckel

8. Performing Organization Report No.

E-4857

10. Work Unit No

9. Performing Organization Name and Address

NASA Lewis Research Center

535-05-01

Cleveland, Ohio 44135-3191

and

Propulsion Directorate

U.S. Army Aviation Research and Technology Activity-AVSCOM

Cleveland, Ohio 44135-3127

12. Sponsoring Agency Name and Address

National Aeronautics and Space Administration

Washington, D.C. 20546-0001

and

U.S. Army Aviation Systems Command

St. Louis, Mo. 63120-1798

11. Contract or Grant No.

15. Supplementary Notes

Prepared for the 25th Joint Propulsion Conference cosponsored by the AIAA, ASME, SAE, and ASEE,

Monterey, California, July 10-12, 1989. Waldo A. Acosta, Propulsion Directorate U.S. Army Aviation Research and Technology Activity-AVSCOM; Stephen A. Beckel, Government Products Division, Pratt \& Whitney

Aircraft, West Palm Beach, Florida. This work was performed as part of NAVY Contract N00140-83-C-8899.

16. Abstract

The performance of an advanced small high temperature rise combustor was experimentally determined at the NASA Lewis Research Center. The combustor was designed to meet the requirements of advanced high temperature, high pressure ratio turboshaft engines. The combustor featured an advanced fuel injector and advanced segmented liner design. The full size combustor was evaluated at power conditions ranging from idle to maximum power. The effect of broad fuel properties was studied by evaluating the combustor with three different fuels. The fuels used were JP-5, a blend of Diesel Fuel Marine/Home Heating Oil (DFM/HHO), and a blend of Suntec $\mathrm{C} /$ Home Heating Oil (SunC/HHO). This paper documents the fuel properties effect on the performance of the combustor in terms of pattern factor, liner temperatures, and exhaust emissions.

17. Key Words (Suggested by Author(s))

Combustor; Pattern factor; Liner temperature; Emissions; Fuel properties; Gas turbine
18. Distribution Statement

Unclassified-Unlimited

Subject Category 07
19. Security Classif. (of this report)

Unclassified
20. Security Classif. (of this page)

Unclassified
21. No of pages

12
22. Price*

A03 